\title{
Growth, growth modelling and age determination of Pandalus borealis
}

\author{
Bo Bergström \\ Kristineberg Marine Biological Station, Kristineberg 2130, S-45034 Fiskebäckskil, Sweden
}

\begin{abstract}
A growth model for pandalid shrimps accounting for seasonal variations in growth is presented based on successive additions of sigmoid functions along a basic von Bertalanffy growth (VBG) equation. Results obtained with this new model are compared with results from the VBG equation and from a VBG model modified by the addition of a sine function. Results show that growth of Pandalus borealis (Krøyer) from Gullmarsfjorden on the Swedish west coast is best described by the seasonal models. Of the 2 seasonal models, the new model gave a slightly better fit. Seasonal variations in growth are discussed in relation to the reproductive cycle of $P$. borealis. Differences in growth pattern between sexes were also found in a 4 yr series of data from the fjord. The main difference was that male growth declined earlier in the year (late summer-autumn) than female growth which declined later (autumn-winter) and for a longer period. Differences in growth rate between sexes are also discussed. Since Gullmarsfjorden contained 4 different periodically isolated $P$. borealis populations during the study period (1984 to 1987), the relationship between growth rate and mean ambient temperature could be investigated in the temperature interval of 4 to $6^{\circ} \mathrm{C}$. No correlation between these 2 factors was found. Results also indicated that recurring immigrations of adult shrimp during late winter-early spring from the Skagerrak population did not significantly affect growth-rate estimates. Finally, sizes by age of $P$. borealis in the fjord did not differ significantly from reported sizes by age in other boreal populations.
\end{abstract}

\section{INTRODUCTION}

Growth of the pandalid shrimp Pandalus borealis (Krøyer) has attracted extensive interest because of its abundance and commercial importance in the north Atlantic and north Pacific Oceans (Shumway et al. 1985). The species has also attracted special interest because of its protandric life cycle and has been used to seek ultimate causes as to why selection maintains protandric reproduction among animals (e.g. Charnov 1979, 1982).

Growth is not easily studied in pandalid shrimps since structures indicating seasonal growth are absent in crustaceans. Furthermore, as in all other crustaceans, growth of individuals is discontinuous due to moulting. Several approaches have been used to determine the age of crustaceans of defined sizes including tagging (e.g. Skúladóttir 1985), lipofuscin assay (Ettershank 1984) and the use of chemical body composition and energy content (Hopkins et al. 1989).

Despite these efforts the most used method of determining growth in seasonally reproducing pandalid shrimps still involves the identification and tracing in time of modes (cohorts) in length-frequency distributions which are generated by the seasonal reproduction. Within these cohorts (year classes) the asynchrony in moulting between individual shrimps is assumed to generate cohorts where carapace lengths are normally distributed. Generally the basic von Bertalanffy growth (VBG) equation (von Bertalanffy 1938, Beverton \& Holt 1957 ) is then fitted by a variety of methods to the mean lengths of these cohorts in relation to their age.

Although the VBG equation has often been used by shrimp biologists to approximate average cohort growth in carapace length (Fréchette \& Parsons 1983) the equation in its original form does not take seasonal variations in growth rate into account. Therefore, the need to develop a growth model specifically for pandalids has been advocated (North Atlantic Fisheries Organisation, NAFO, 'Working Group on Progress in Age Determination of Pandalus', Reykjavik, Iceland 1989). Such a model should incorporate seasonal variations in growth (Bergström 1989, Parsons 1989). Such variations in growth of pandalid shrimps are 
apparent in older studies (e.g Berkeley 1930, Rasmussen 1953, Haynes \& Wigley 1969, Shumway et al. 1985), but not until recently have attempts to use growth models incorporating seasonal variations in growth been made in pandalids. In a recent study by Hopkins \& Nielssen (1990), growth of P. borealis in Balsfjord (northern Norway) was found to be better described by a VBG function modified for seasonal oscillations in growth compared with the original VBG function.

This paper presents a revised model for pandalid shrimps incorporating seasonal variations in growth by the successive addition of sigmoid functions along a basic VBG equation. The work with this model was also motivated by the inability of both the basic VBG and already published VBG equations modified for seasonal growth (Pauly \& Gaschutz 1978) to describe sigmoid growth. Results obtained with this model are compared with results from the basic VBG and from a VBG model modified by the addition of a sine function developed by Pauly \& Gaschutz (1978). The models are applied to new data obtained from a stock of Pandalus borcalis in Cullmarsfjorden on the Swedish west coast (Bergström 1991a, b).

The traditionally used VBG equation is often applied to samples where males and females are pooled. This practice may not take into account differences in growth between the 2 sexual stages. Indications of such differences in Pandalus borealis were mentioned (Rasmussen 1953, Allen 1959) and observed in a preliminary study by Bergström (1989). This paper also discusses sex-differentiated growth in $P$. borealis based on 4 yr (1984 to 1987) of empirical data containing 7 identifiable year classes (1980 to 1986) from the fjord. Growth curve parameters have been estimated both for pooled samples (containing both males and females) and for the individual sexual stages.

Most studies on growth of Pandalus borealis have been carried out in populations in the open sea or in fjords with no effective sill where the definition of a stock or population may be more related to fishing activity than to ecological factors. In Gullmarsfjorden periodical isolates (shrimp demes) of the Skagerrak population are trapped during deep-water stagnation periods (Bergström 1991a). Using this phenomenon this paper also discusses the effect of yearly immigrations of post-larval shrimp into these demes on growth estimation.

Finally, sizes by age predicted with mean growth models for male and female Pandalus borealis in Gullmarsfjorden are compared with published sizes by age from other populations in order to evaluate if the growth pattern observed in Gullmarsfjorden may represent growth patterns common among shrimp populations found in other localities at boreal latitudes.

\section{MATERIALS AND METHODS}

Study area. In the shallow-silled Gullmarsfjorden (Fig. 1) a small stock of Pandalus borealis is found. Gullmarfjorden has a maximum depth of $120 \mathrm{~m}$. The deep basin is separated from the deeper parts of the Skagerrak by a sill with an effective depth of approximately $50 \mathrm{~m}$ (Fig. 1). The water-body in the fjord is normally stratified in 3 layers (Lindahl \& Hernroth 1988) (Fig. 1).

Shrimp are found in the deep basin below $50 \mathrm{~m}$. During periods of deep-water stagnation true, albeit short-lived, shrimp populations/demes formed between yearly deep-water renewals. These populations/demes are periodical isolates of the Skagerrak stock enclosed by different salinity and temperature regimes in the water layers above sill depth during 8 to 12 mo (Bergström 1991a). In the deep basin the water is characterised by salinities greater than $34 \%$ and low stable temperatures $\left(4\right.$ to $6^{\circ} \mathrm{C}$ ). The water exchange which normally occurs in January to April each year

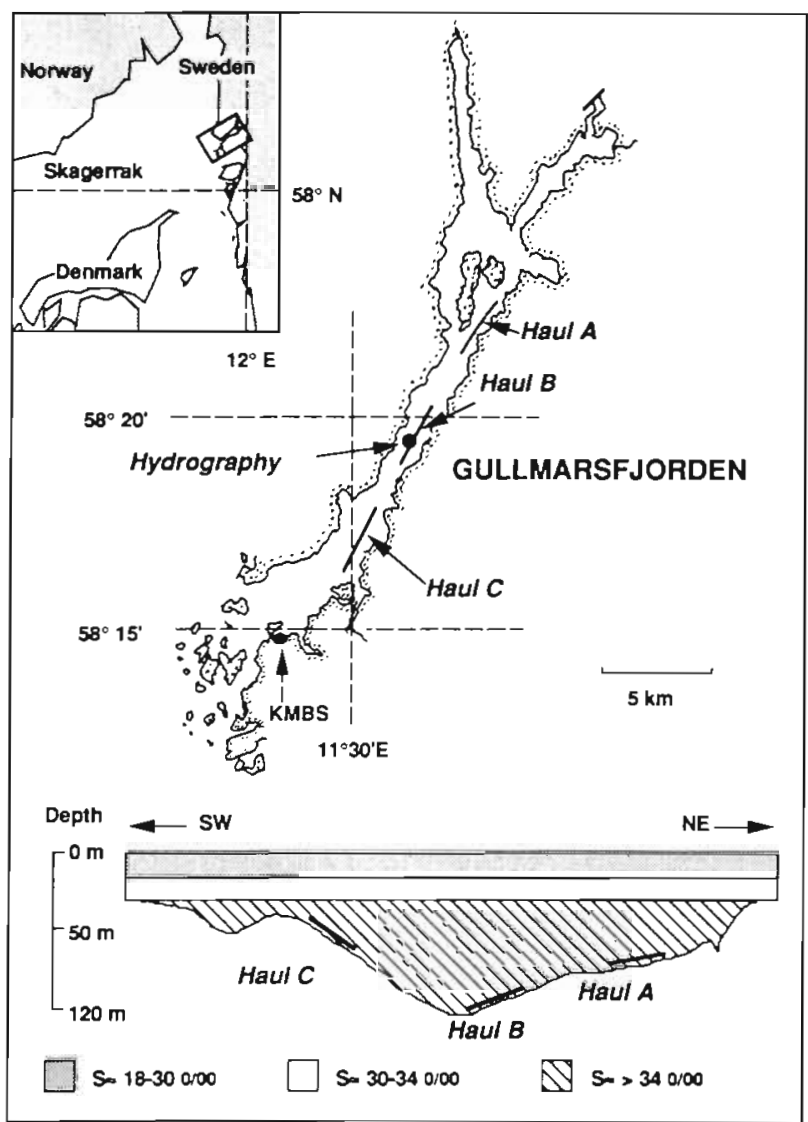

Fig. 1 Sampl.ng locations and depth profile of Gullmarsfjorden. The 3 separate hauls comprising the fishing effort of 1 sampling day are shown as well as the hydrography station. Approximate positions of the 3 normal water layers of the fjord are indicated in the depth profile 
takes the form of one or several smaller or larger intrusions of cold and saline water (Lindahl \& Hernroth 1988).

During 3 (1984, 1985, and 1987) out of 4 water exchange periods new demographic patterns in the fjord shrimp population were formed at the beginning of the year by immigration of older shrimp over the sill area. During the fourth year (1986) recruitment of a new younger year class dominated the demographic pattern (Bergström 1991a). Preliminary results regarding growth of Pandalus borealis in Gullmarsfjorden were discussed by Bergström (1989).

Sampling. Three designated sites in the fjord were trawled during the same day. These sites (Fig. 1) represented different levels below sill depth and were chosen to yield a pooled sample that represented the stock in the ca $2 \mathrm{~km}$ wide and $18 \mathrm{~km}$ long deep basin of the fjord. Haul A was situated in the innermost part of the fjord at depths of 77 to $80 \mathrm{~m}$. Haul B was made in the central part of the deep basin at 110 to $116 \mathrm{~m}$ of depth. Haul $\mathrm{C}$ was taken on the northeast (inner) part of the sill slope at depths of 64 to $71 \mathrm{~m}$. For the purpose of this growth study, the 3 samples from each sampling day were pooled. A total of 42 such samples were obtained containing a total of 15312 specimens of Pandalus borealis.

An otter trawl with a maximal stretched foot rope length of $9 \mathrm{~m}$ was used. Mesh size in the cod end, measured as square bar length, was $18 \mathrm{~mm}$. Cruising speed was maintained at 2.5 knots and fishing time on the bottom was $30 \mathrm{~min}$. The same trawl and procedure were used throughout the study. Positioning was done using landmarks (Bergström 1991a).

The catch of Pandalus borealis in each haul was analysed upon return to the laboratory. The oblique carapace length (CPL; Rasmussen 1953) of each shrimp was measured with callipers to within $0.1 \mathrm{~mm}$. Sex of each shrimp was determined on the basis of the shape of the first pleopod endopodite according to Allen (1959).

Growth models. Three equations describing growth in length were fitted to mean CPL at age. The VBG equation was used in its original form

$$
L_{t}=L_{\infty}\left(1-\mathrm{e}^{-K\left(t-t_{0}\right)}\right)
$$

where $L_{t}=$ carapace length at age $t_{i} L_{\circ}=$ asymptotic carapace length; $K=$ growth coefficient; $t=$ age; $t_{0}=$ age at length 0 .

This equation was later modified by Pauly \& Gaschutz (1978) who added a sine function (VBG sine $_{\text {) }}$ ) to describe seasonal variations in growth:

$$
L_{t}=L_{\infty}\left[\left(1-\mathrm{e}^{-K\left(t-t_{0}\right)}\right)+(C K / 2 \pi) \sin 2 \pi\left(t-t_{0}-t_{s}\right)\right]
$$

where $C=$ degree of seasonality; $t_{s}=$ seasonal phase constant, $W P_{\text {sine }}-0.5$; and $W P_{\text {sine }}=$ the winter point, the date of slowest growth during the year.

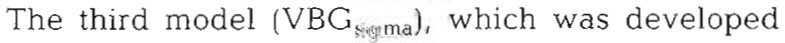
for this study, is also a modification of the VBG but seasonal variations in growth are represented by the use of periodically recurring sigmoid functions. The following symbols are used: $P=$ period (in the case of Pandalus borealis in Gullmarsfjorden $P$ was assumed to be 1 yr); $n=$ period or season number; $b=$ constant determining shape of sigmoid; $t_{n}=W P_{\text {sigma }}+(n-1) P$; and $W P_{\text {sigma }}=$ the seasonal phase constant, the time of year when the growth rate $=0$.

If seasons are assumed to have a duration of $P$, lifetime growth can be partitioned in seasons by defining points of time $t_{1}, t_{2} \ldots t_{n}$ with a reciprocal distance of $P$ This can be represented by

$$
t_{n}=t_{1}+(n-1) P \quad n=1,2,3 \ldots
$$

where $t_{n}$ represents the winter point, the point of slowest growth during the season, $n$. Growth at $t_{1}$, $t_{2} \ldots t_{n}$ is then assumed to follow the von Bertalanffy equation

$$
L\left(t_{n}\right)=L_{\infty}\left(1-\mathrm{e}^{-K\left(t_{n}\right)}\right) \quad n=1,2,3 \ldots
$$

which will give the starting point for growth during the season, $n$. However to be able to describe the growth pattern fully, the function

$$
L(t)=L_{\infty}\left(1-\mathrm{e}^{-K\left(t_{n}\right)}\right)+S(t) \quad t_{n} \leq t \leq t_{n+1}
$$

was used where $S(t)$ describes seasonal growth. Two important conditions must be met by $S(t)$ :

1. $S\left(t_{n}\right)=0$ and

2. $S\left(t_{n+1}\right)=L_{\infty}\left(1-\mathrm{e}^{-K\left(l_{n}\right)}-\mathrm{e}^{-K\left(t_{n+1}\right)}\right)$.

If these conditions are met the seasonal growth curves join together. It then remains to find a sigmoid expression for $S(t)$. First consider the simple sigmoid function:

$$
1 /\left(1+e^{-b t}\right)
$$

where $b$ is a constant determining the curvature. This curve gives a maximal growth rate when $t=0$, but for the purpose of this study it is desirable to get maximal growth at $t=t_{n}+P / 2$, which leads us to the expression

$$
1 /\left(1+e^{-b\left(t-t_{n}-P / 2\right)}\right)
$$

In order to satisfy Condition 1, we form the expression

$$
1 /\left(1+e^{-b\left(t-t_{n}-P / 2\right)}\right)-1 /\left(1+e^{b P / 2}\right)
$$


To satisfy Condition 2, we multiply by a constant, $C$. The expression for $C$ becomes relatively complicated:

$$
C=L_{\infty} \mathrm{e}^{-K\left(t_{n}\right)}\left(1-\mathrm{e}^{-K P}\right)\left[\left(1+\mathrm{e}^{-b P / 2}\right)\left(1+\mathrm{e}^{b P / 2}\right) /\left(\mathrm{e}^{b P / 2}-\mathrm{e}^{-b P / 2}\right)\right] .
$$

The function $S(t)$ then becomes:

$$
\begin{aligned}
S(t)= & L_{\infty} \mathrm{e}^{-K\left(t_{\Pi}\right)}\left(1-\mathrm{e}^{-K P}\right)\left(1+\mathrm{e}^{-b P / 2}\right) \\
& /\left(\mathrm{e}^{b P / 2}-\mathrm{e}^{-b P / 2}\right)\left[\left(1+\mathrm{e}^{b P / 2}\right) /\left(1+\mathrm{e}^{-b\left(t-t_{n}-P / 2\right)}\right)-1\right]
\end{aligned}
$$

The complete growth equation then reads

$$
\begin{aligned}
L(t)= & L_{\infty}\left\{1-\mathrm{e}^{-K\left(t_{n}\right)}+A\left[\left(1+\mathrm{e}^{b P / 2}\right)\right.\right. \\
& \left.\left./\left(1+\mathrm{e}^{-b\left(t-t_{n}-P / 2\right)}\right)-1\right]\right\} \quad t_{n} \leq t \leq t_{n+1}
\end{aligned}
$$

where

$$
A=e^{-K\left(t_{D}\right)}\left(1-e^{-K P}\right)\left(1+e^{-h P / 2}\right) /\left(e^{b P / 2}-e^{-h P / 2}\right) .
$$

In both models modified for seasonal growth, mean CPL of shrimp at the date of slowest growth (WP) indicates the growth result of the previous growth season. Since hatching date is assumed to be on 15 March in Gullmarsfjorden, WP estimates in both models can be converted to dates by use of the formula:

$[(W P \times 365)+76] / 30.41=$ date $($ in mo) since hatching

In this formula the year consists of $365 \mathrm{~d}$ split into 12 standard months ( $30.41 \mathrm{~d})$. The number 76 denotes the number of days from 1 January to the assumed hatching date, 15 March, and is used as a constant to adapt $W P$ to the calendar year. For simplicity the CPL at hatching was assumed to be $0 \mathrm{~mm}$. Gallucci \& Quinn (1979) showed that small variations around 0 in initial length did not seriously affect the later span of VBG based growth curves.

Fitting of the growth models to the estimated average cohort CPLs, weighted by number of shrimp in the different cohorts, was in all cases achieved with the least square method implemented in the PC program 'Statgraphics'. The weighting of the average cohort CPLs by number of shrimp is especially important for the comparison of growth rates between the sexual stages. In a sample of this basically protandric species the number of young males is normally much greater than the number of young females. Similarly the number of large/old males is very small compared to the number of large/old females.

Length-frequency distributions and cohort separation. Growth estimation in seasonally reproducing pandalid shrimps involves the tracing in time of modes (cohorts) in length-frequency distributions (LFD) and the determination of mean length and variance of these modes. Due to the well-defined yearly hatching period of Pandalus borealis in the spring (e.g. Bergström 1991b) the cohorts can be assigned discrete ages based on an estimated mean hatching date. For the purpose of this study mean hatching date was assumed to be 15 March for all year classes based on the results of Bergstrom (1991b). Length at the hatching date $\left(L_{0}\right)$ was approximated to $0 \mathrm{~mm}$ for simplicity reasons. It was also motivated by the fact that $P$. borealis larvae go through a planktonic stage where the newly hatched larvae have a carapace length of approximately $1 \mathrm{~mm}$ which is very close to 0 . Gallucci \& Quinn (1979) showed that very small variations in $L_{0}$ did not seriously affect the estimates of $K$ and $L_{\infty}$ in VBG based growth models which mainly are fitted to sizes at older ages.

When calculating and plotting the LFDs, measurements were pooled in $0.5 \mathrm{~mm}$ size classes. Separation of cohorts assumed to represent year classes in the LFDs as well as estimation of mean size by age were made using the computer program MIX 2.3 (Macdonald \& Pitcher 1979, Macdonald 1987). This program enabies the user to anaiyse length-frequency histograms by finding sets of best-fitting normal distributions. To facilitate comparisons with data in older literature where total lengths are presented instead of carapace lengths, Table 1 presents mean conversion factors between carapace length and total length for shrimp in Gullmarsfjorden. Measurements were made on 157 shrimps (41 females and 116 males) from a sample taken 1 July 1987 . Linear regressions describing the relationship between total length and carapace length were also calculated using the least square method

Data analyses. Data were analysed by year class ('year class wise') and by deep-water stagnation period ('stagnation wise'). In each case ('year class wise' and 'stagnation wise') data were treated both separated by sexual stage and as pooled.

Year classes were followed for as long as possible

\begin{tabular}{|c|c|c|c|}
\hline & $N$ & $\begin{array}{c}\text { Mean conversion } \\
\text { factor } \pm S D\end{array}$ & Regression \\
\hline Pooled & 157 & $5.71 \pm 0.22$ & $\begin{array}{c}\mathrm{TL}=11.78+5.13 \mathrm{CPL} ; \\
\mathrm{R}^{2}=0.948\end{array}$ \\
\hline Males & 116 & $5.77 \pm 0.23$ & $\begin{aligned} \mathrm{TL}= & 4.45+5.56 \mathrm{CPL} \\
& \mathrm{R}^{2}=0.954\end{aligned}$ \\
\hline Females & 41 & $5.65 \pm 0.21$ & $\begin{array}{c}\mathrm{TL}=13.19+5.00 \mathrm{CPL} \\
\mathrm{R}^{2}=0.930\end{array}$ \\
\hline
\end{tabular}
throughout the study period. In these analyses samples

Table 1. Pandalus borealis. Conversion factors and regression equations relating oblique carapace length (CPL) to total length (TL) of shrimps un Gullmarsfjorden. Size range: males, 11 to $23 \mathrm{~mm} \mathrm{CPL}$ females, 14 to $30 \mathrm{~mm} \mathrm{CPL}$ 
taken in the fjord during the water renewal as well as stagnation periods were included. This strategy assumed that growth conditions during the deep-water stagnation periods in Gullmarsfjorden and Skagerrak were sufficiently similar so as not to disrupt a continuous growth curve regardless of immigrations to the fjord during the water renewal periods.

Growth was also analysed 'stagnation wise', excluding samples taken during the water renewals. One motive for analysing data from the 4 stagnation periods separately was to investigate if the yearly immigration of shrimp into the temporally enclosed fjord populations/demes (Bergström 1991a) significantly affected the growth rate estimates.

Another motive was to investigate the possible relationship between mean ambient temperature and growth rate. During the 4 separate periods mean temperatures in the deep basin of the fjord were slightly different (Bergström 1991b) (see also Table 5), which gave an opportunity to test if mean ambient temperature could be correlated with growth rate.

In 1984, 1985 and 1986 the stagnation periods lasted from mid April to late January the following year, while in 1987 the deep-water stagnation began near the end of February. In 1984, 1985 and 1986, 8 such pooled samples were used for this analysis, while in 1987 only 6 samples were used. When using samples taken only during the periods of deep-water stagnation, growth curves were fitted to consecutive year classes identified in the samples assuming that year classes generally are spread 1 yr apart.

Comparison of growth rates. Since $L_{\infty}$ and $K$ are negatively related to each other, comparisons of estimated growth rates in time (between areas or sexes or for estimation methods) are problematical (Gallucci \& Quinn 1979). Thus comparison of growth rates estimated with the 3 different models both 'year class wise' and 'stagnation wise' was done by reparameterizing the 3 different VBG models, and tests were performed on a new, single parameter,

$$
\Omega=K L_{\infty}
$$

The parameter $\Omega$ corresponds to the growth rate near $t_{0}$ and is suitable for comparisons because of its statistical robustness (Gallucci \& Quinn 1979). This parameter was subjected to unpaired 2-tailed t-tests (Sokal \& Rohlf 1969).

Growth rate and temperature. Since the mean tem perature varied between the studied deep-water stagnation periods (Bergström 1991b) (see also Table 5) it was possible to test the effect of temperature on growth rate in the temperature interval of 4 to $6{ }^{\circ} \mathrm{C}$. This was done in 2 different ways. First, temperatures were correlated with the parameter $\Omega$ estimated from the pooled samples analysed 'stagnation wise' Secondly, by assuming that growth during the yearly period of accelerated growth (spring and summer) was linear, regressions were fitted to CPL at age (males only, 1 to $2 \mathrm{yr}$ old) for each of the stagnation periods The resulting regression coefficients and mean ambient temperatures were then subjected to correlation analyses.

Growth of Pandalus borealis in Gullmarsijorden compared with other populations. Very few reports concerning growth in $P$. borealis give fitted growth curves and parameters, while sizes by age are frequently reported. Thus sizes by age predicted by the mean male and female $V_{B G_{\text {sigma }}}$ functions derived from the investigation in Gullmarsfjorden were compared with sizes by age reported from other boreal populations using a 1 -group $\chi^{2}$ test. This comparison was done in order to evaluate the results from Gullmarsfjorden. Sex-differentiated sizes by age from the North Sea, Northumberland coast, UK (Allen 1959), Burrard Inlet, British Columbia, Canada (Butler 1964), Gulf of Maine, USA (Haynes \& Wigley 1969) and Oslofjorden, Norway (Rasmussen 1953) were used.

\section{RESULTS}

\section{Mean carapace length at sampling date}

Length-frequency distributions and numbers of males, transitionals and females are presented in Fig. 2 along with total number, number of males, transitionals and females. Mean carapace lengths with standard deviation weighted by number of shrimp in the cohort at sampling dates of cohorts throughout the study period are presented in Fig. 3. Females of similar age as males were in general slightly larger, a size difference which was especially noticeable for age $\geq 2$ yr (Fig. 3). Transitional shrimps which appeared in the samples from late winter-late spring were in general slightly larger than males of the same age. A seasonal pattern of growth was also discernible in both sexes and all age groups.

As shown in Fig. 3 cohorts of shrimp hatched in spring 1980 could still be identified with MIX during the summer of 1985, and at age $=\mathrm{ca} 5.3 \mathrm{yr}$, these had reached a CPL of $28.1 \pm 1.2 \mathrm{~mm}$ ( $\mathrm{TL}=146$ to $171 \mathrm{~mm}$ ) and were all females. Larger shrimps with a CPL of 30 to $32 \mathrm{~mm}$ (TL $=163$ to $188 \mathrm{~mm}$ ) occurred regularly in the samples from Gullmarfjorden. These female shrimps which were older than 5 yr were, however, too few to be identified as separate cohorts. Females of all sizes and ages where found in the samples (Figs. $2 \& 3$ ), but young females (<1.5 yr old) were generally much rarer than males of the same 

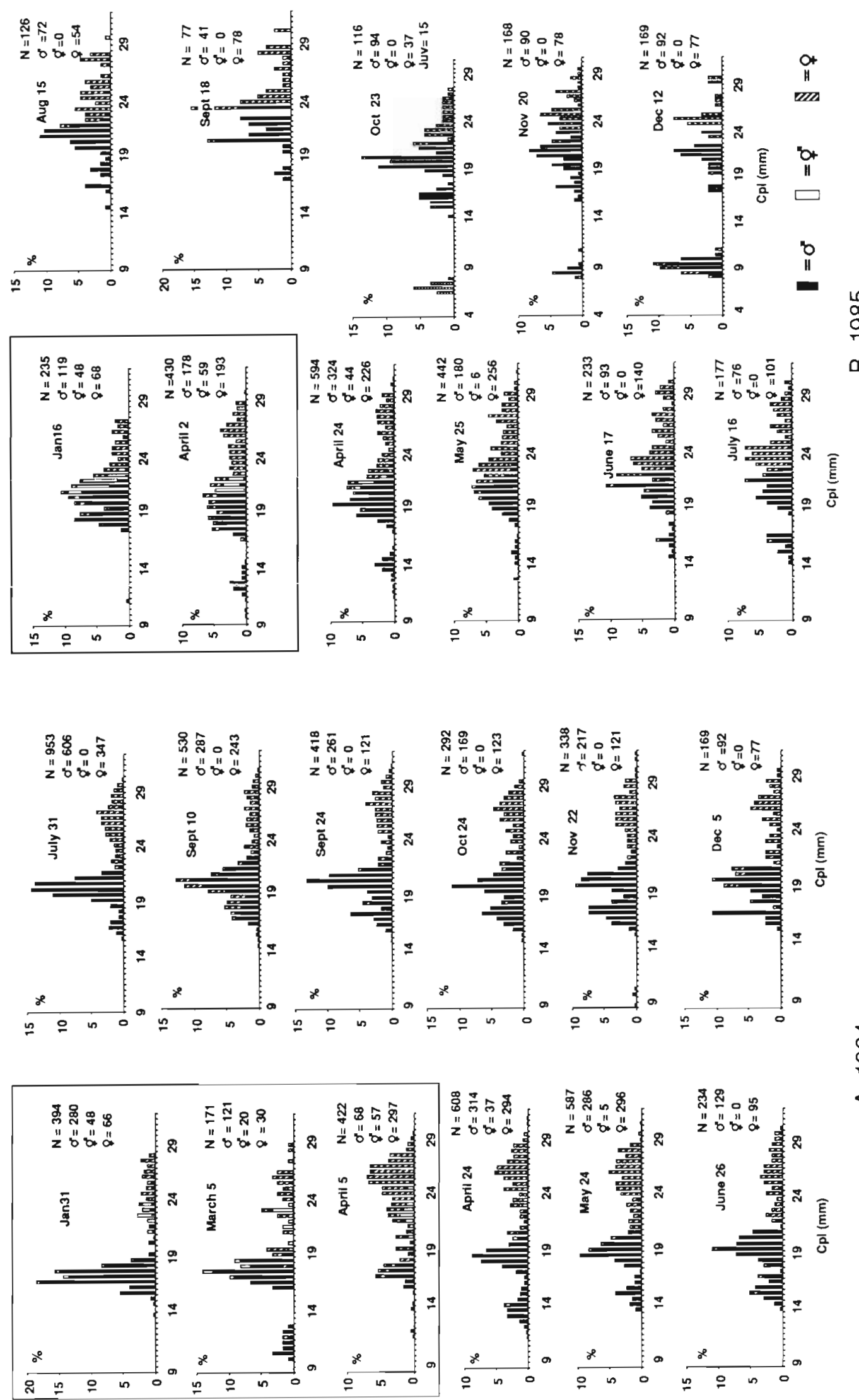

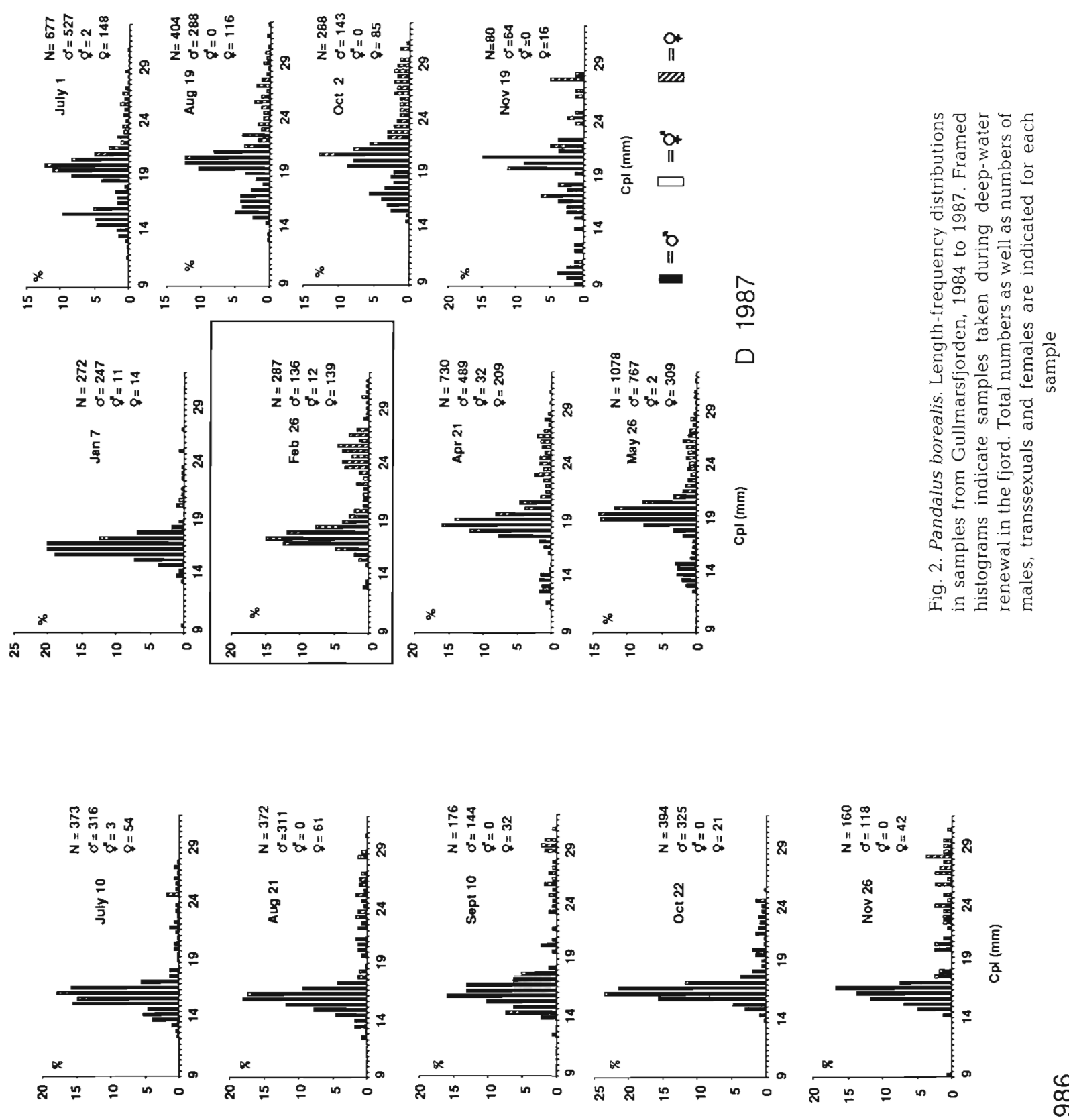

@

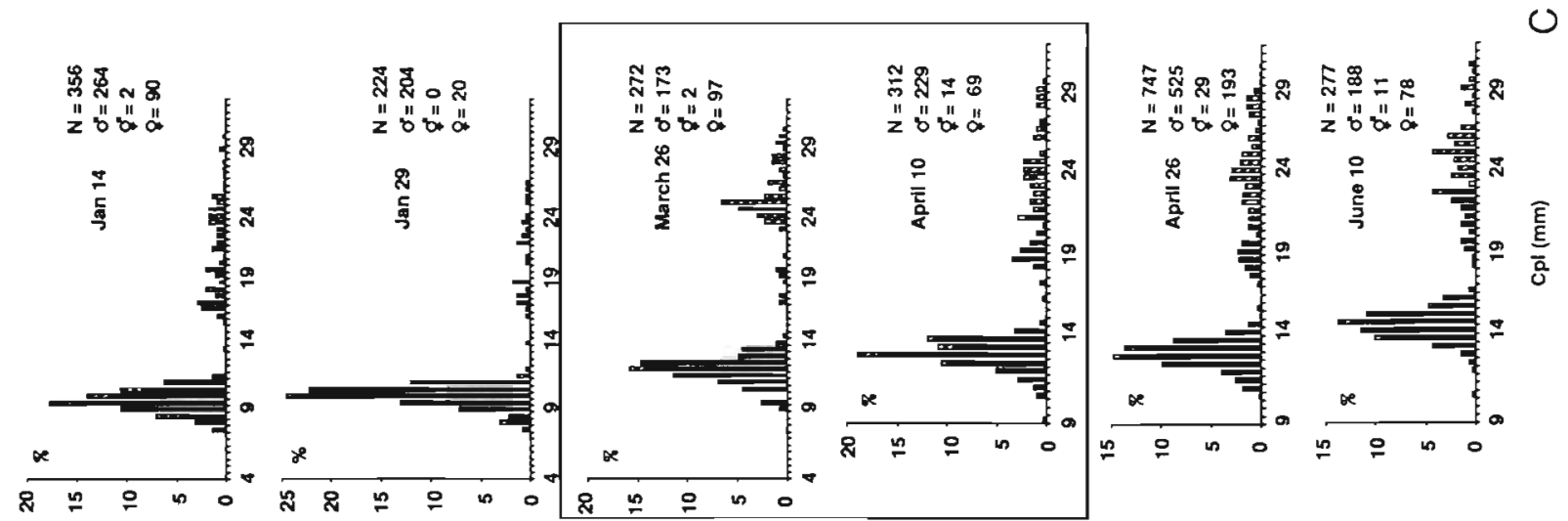



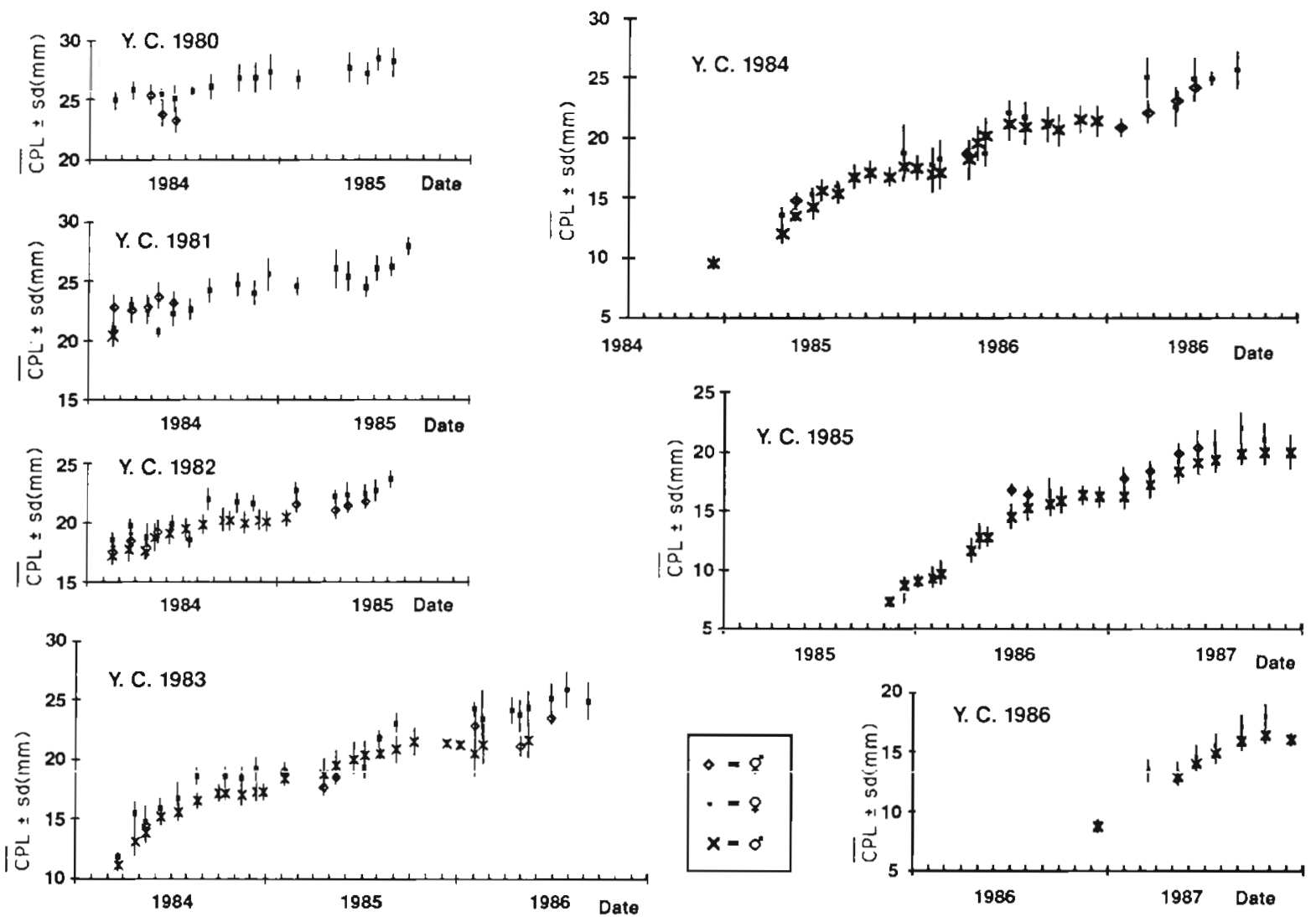

Fig. 3. Pandalus borealis. Mean carapace length $(\overline{\mathrm{CPL}})$ and standard deviation at sampling date of male, transsexual, and female shrimps in year classes 1980 to 1986 from Gullmarsfjorden

age. Generally the male stage did not last more than $2.8 \mathrm{yr}$, by which age they had a CPL of 20.1 to $22.2(\mathrm{~mm})$ ( $\mathrm{TL}=111$ to $133 \mathrm{~mm}$ ). Exceptions were 4 specimens found in 1987, which had CPLs of 25.0 to $28.0 \mathrm{~mm}$. (TL $=139$ to $168 \mathrm{~mm}$ ). These shrimp which hatched in 1983 were still males at an age of more than 4 yr. Transitional shrimps which always were larger than average males of the same age generally occurred in spring and early summer (Fig. 2). These shrimps occurred in small numbers in all age groups (Figs. 2 \& 3). The approximate mean ages of these sex changers were 12.4 mo (mean $\mathrm{CPL}=13.3 \mathrm{~mm}$ ), 23 mo $($ mean $\mathrm{CPL}=17.5 \mathrm{~mm}), 35.4$ mo $($ mean $\mathrm{CPL}=$ $21.8 \mathrm{~mm}$ ) and $50 \mathrm{mo}$ (mean $\mathrm{CPL}=23.3 \mathrm{~mm}$ ) (Figs. 3 \& 5). Of these transitional shrimp the group with an estimated age of ca 3 yr were always most abundant.

\section{Comparison of growth models}

Parameters and coefficient of determination $\left(R^{2}\right)$ for all year classes and stagnation periods are presented in Tables $2 \& 3$ along with calculated growth rates at $t_{0}$ $(\Omega)$. Growth curves generated by the 3 different mod- els are illustrated for the year class 1985 in Fig. 4. In general the 2 seasonal models gave better fits to the data than the unmodified VBG equation. Of these 2, the model with sigmoid oscillation often gave slightly higher coefficients of determination than the sine model (Tables $2 \& 3$ ). This general difference was less pronounced when data were analysed 'stagnation wise' rather than 'year class wise' A statistical comparison of $\Omega$ calculated from the growth curve parameters $K$ and $L_{\infty}$ estimated with the 3 different models shows that there were no differences in the estimated growth rates at the $95 \%$ confidence level (Table 4 ). When the sine models were fitted to female data, the best-fitting solution often gave values of $C>1$ which signifies negative growth during the growth stagnation period, although the empirical data did not show such a trend (Fig. 3). Fitting the seasonal models to the data set from the 1986 year class failed due to small numbers of females.

Both seasonal growth models estimate the date of slowest growth of the year Confidence intervals for $W P_{\text {sine }}$ and $W P_{\text {sigma }}$ are given together with calculated dates in Table 3 . Results from both models indicate that the cessation of growth in carapace length occurred 
Table 2. Pandalus borealis. Best-fitting growth model parameters obtained from fitting 3 growth models $\left(V B G, V G_{\text {sine }}, V_{B G} G_{\text {signa }}\right)$ to mean carapace lengths at age of year classes from Gullmarsfjorden. Parameters and definitions for Tables 2 \& $3 . L_{\infty}$ : Asymptotic carapace length; $K$ : growth coefficient; $\Omega$ : growth rate at time $=0$; $C$ : degree of seasonality; $W P_{\text {sme }}$ : the winter point, the date of slowest growth during the year; $b$ : constant determining shape of sigmoid; $W P_{\text {sigma }}$ : the seasonal phase constant, the time of year when the growth rate $=0 ; \mathrm{Cl}: 95 \%$ confidence interval $(p \geqslant 0.005)$

\begin{tabular}{|c|c|c|c|c|c|c|c|c|c|}
\hline Parameter & 1980 & 1981 & 1982 & 1983 & 1984 & 1985 & 1986 & Mean $W P \pm C I$ & Slow growth period \\
\hline \multicolumn{10}{|l|}{ VBG ơ } \\
\hline$L_{\infty}$ & & & 27.24 & 27.58 & 31.36 & 25.61 & 24.76 & & \\
\hline$K$ & & & 0.54 & 0.61 & 0.48 & 0.62 & 0.70 & & \\
\hline$\Omega$ & & & 14.79 & 16.69 & 15.14 & 15.87 & 17.43 & & \\
\hline $\mathrm{R}^{2}$ & & & 0.507 & 0.748 & 0.758 & 0.892 & 0.602 & & \\
\hline \multicolumn{10}{|l|}{$\mathrm{VBG}_{\text {sine }}$ ơ } \\
\hline$L_{\infty}$ & & & 27.05 & 28.07 & 31.21 & 24.27 & \multirow{6}{*}{ Failed } & & \\
\hline$K$ & & & 0.55 & 0.58 & 0.48 & 0.68 & & & \\
\hline C & & & 0.58 & 0.78 & 0.59 & 0.81 & & & \\
\hline$W P_{\text {sine }}$ & & & 0.52 & 0.62 & 0.55 & 0.60 & & $0.51 \pm 0.08$ & $13 \mathrm{Sep}-21 \mathrm{Oct}$ \\
\hline$\Omega$ & & & 14.77 & 16.28 & 15.07 & 16.58 & & & \\
\hline $\mathrm{R}^{2}$ & & & 0.536 & 0.768 & 0.768 & 0.915 & & & \\
\hline \multicolumn{10}{|c|}{$\mathrm{VBG}_{\text {sigma }} \sigma^{\circ} \varnothing$} \\
\hline$L_{\infty}$ & & & 26.88 & 27.76 & 30.81 & 23.76 & \multirow{6}{*}{ Failed } & & \\
\hline$K$ & & & 0.56 & 0.60 & 0.50 & 0.73 & & & \\
\hline$b$ & & & 5.3 & 7.02 & 5.73 & 6.90 & & & \\
\hline$W P_{\text {sigma }}$ & & & 0.46 & 0.57 & 0.49 & 0.55 & & $0.52 \pm 0.08$ & $21 \mathrm{Aug}-21 \mathrm{Oct}$ \\
\hline$\Omega$ & & & 15.13 & 16.76 & 15.50 & 17.44 & & & \\
\hline $\mathrm{R}^{2}$ & & & 0.536 & 0.765 & 0.768 & 0.915 & & & \\
\hline \multicolumn{10}{|l|}{ VBG o } \\
\hline$L_{\infty}$ & & & 25.26 & 24,04 & 27.79 & 24.98 & \multirow{4}{*}{$\begin{array}{c}25.49 \\
0.67 \\
17.00 \\
0.628\end{array}$} & & \\
\hline$K$ & & & 0.63 & 0.79 & 0.59 & 0.65 & & & \\
\hline$\Omega$ & & & 15.91 & 18.99 & 16.37 & 16.11 & & & \\
\hline $\mathrm{R}^{2}$ & & & 0.534 & 0.806 & 0.843 & 0.892 & & & \\
\hline \multicolumn{10}{|l|}{$\mathrm{VBG}_{\text {sine }} \sigma^{*}$} \\
\hline$L_{c o s}$ & & & 23.06 & 24.47 & 27.91 & 23.79 & \multirow{6}{*}{ Failed } & & \\
\hline$K$ & & & 0.788 & 0.751 & 0.58 & 0.705 & & & \\
\hline$C$ & & & 0.925 & 0.817 & 0.993 & 0.132 & & & \\
\hline$W P_{\text {sine }}^{\prime}$ & & & 0.651 & 0.624 & 0.414 & 0.607 & & $0.57 \pm 0.17$ & $10 \mathrm{Aug}-14 \mathrm{Dec}$ \\
\hline$\Omega$ & & & 18.17 & 18.38 & 16.19 & 16.77 & & & \\
\hline $\mathrm{R}^{2}$ & & & 0.577 & 0.825 & 0.867 & 0.917 & & & \\
\hline \multicolumn{10}{|l|}{$\mathrm{VBG}_{\text {sigma }} \sigma^{\prime}$} \\
\hline$L_{\infty}$ & & & 23.08 & 24.14 & 27.55 & 23.31 & \multirow{6}{*}{ Failed } & & \\
\hline$K$ & & & 0.80 & 0.80 & 0.60 & 0.76 & & & \\
\hline$b$ & & & 7.60 & 7.24 & 9.37 & 7.03 & & & \\
\hline$W P_{\text {sigma }}$ & & & 0.59 & 0.56 & 0.55 & 0.55 & & $0.56 \pm 0.03$ & $26 \mathrm{Sep}-16 \mathrm{Oct}$ \\
\hline$\Omega$ & & & 18.51 & 19.22 & 16.61 & 17.69 & & & \\
\hline $\mathrm{R}^{2}$ & & & 0.577 & 0.826 & 0.868 & 0.917 & & & \\
\hline \multicolumn{10}{|l|}{ VBG $q$} \\
\hline$L_{\infty}$ & 32.68 & 35.6 & 25.43 & 28.86 & 30.48 & 31.15 & \multirow{4}{*}{$\begin{array}{c}32.57 \\
0.50 \\
16.38 \\
0.634\end{array}$} & & \\
\hline$K$ & 0.37 & 0.32 & 0.70 & 0.60 & 0.53 & 0.46 & & & \\
\hline$\Omega$ & 11.93 & 11.36 & 17.78 & 17.14 & 16.03 & 14.45 & & & \\
\hline $\mathrm{R}^{2}$ & 0.532 & 0.492 & 0.613 & 0.792 & 0.621 & 0.92 & & & \\
\hline \multicolumn{10}{|l|}{$\mathrm{VBG}_{\text {sine }}$ ? } \\
\hline$L_{\infty}$ & 32.31 & 36.43 & 25.33 & 28.76 & 30.39 & 27.19 & \multirow{6}{*}{ Fãiled } & & \\
\hline$K$ & 0.38 & 0.31 & 0.73 & 0.61 & 0.54 & 0.60 & & & \\
\hline C & 0.89 & 0.63 & 1.00 & 1.00 & 0.58 & 0.87 & & & \\
\hline$W P_{\text {sine }}$ & 0.98 & 0.88 & 0.81 & 0.71 & 0.89 & 0.65 & & $0.82 \pm 0.13$ & 24 Nov-27 Feb \\
\hline$\Omega$ & 12.31 & 11.14 & 18.41 & 17.51 & 16.44 & 16.21 & & & \\
\hline $\mathrm{R}^{2}$ & 0.455 & 0.514 & 0.669 & 0.811 & 0.624 & 0.935 & & & \\
\hline $\mathrm{VBG}_{\text {sigma }}$ ? & & & & & & & & & \\
\hline$L_{\infty}$ & 32.19 & 36.33 & 25.33 & 28.57 & 29.82 & 26.51 & & & \\
\hline$K$ & 0.39 & 0.31 & 0.76 & 0.63 & 0.58 & 0.64 & & & \\
\hline$b$ & 7.95 & 6.32 & 23.91 & 8.68 & 6.38 & 7.3 & & & \\
\hline$W P_{\text {sigmat }}$ & 0.94 & 0.83 & 0.80 & 0.66 & 0.81 & 0.61 & Failed & $0.78 \pm 0.139$ & 8 Nov-11 Feb \\
\hline$\Omega$ & 12.55 & 11.26 & 19.25 & 18.00 & 17.30 & 16.17 & & & \\
\hline $\mathrm{R}^{2}$ & 0.455 & 0.514 & 0.669 & 0.811 & 0.624 & 0.935 & & & \\
\hline
\end{tabular}


Table 3. Pandalus borealis. Same as Table 2 but for deep-water stagnation periods in Gullmarsfjorden

\begin{tabular}{|c|c|c|c|c|c|c|}
\hline Parameter & 1984 & 1985 & 1986 & 1987 & Mean $W P \pm C I$ & Slow growth period \\
\hline \multicolumn{7}{|l|}{ VBG ơ } \\
\hline$L_{\infty}$ & 28.11 & 28.72 & 31.70 & 31.23 & & \\
\hline$K$ & 0.54 & 0.53 & 0.47 & 0.44 & & \\
\hline$\Omega$ & 15.18 & 15.25 & 14.96 & 13.80 & & \\
\hline $\mathrm{R}^{2}$ & 0.637 & 0.759 & 0.87 & 0.752 & & \\
\hline \multicolumn{7}{|c|}{$\mathrm{VBG}_{\text {sine }} \sigma^{\prime} Q$} \\
\hline$L_{\infty}$ & 28.30 & 28.82 & 32.70 & 34.0 & & \\
\hline$K$ & 0.52 & 0.52 & 0.43 & 0.36 & & \\
\hline$C$ & 1.23 & 1.28 & 1.57 & 3.08 & & \\
\hline$W P_{\text {sine }}$ & 0.596 & 0.363 & 0.446 & 0.436 & $0.461 \pm 0.156$ & $5 \mathrm{Jul}-27 \mathrm{Oct}$ \\
\hline$\Omega$ & 14.83 & 14.93 & 14.58 & 12.21 & & \\
\hline $\mathrm{R}^{2}$ & 0.636 & 0.759 & 0.883 & 0.778 & & \\
\hline \multicolumn{7}{|c|}{$\mathrm{VBG}_{\text {sigma }}$ of } \\
\hline$L_{\infty}$ & 28.21 & 28.72 & 32.28 & 33.71 & & \\
\hline$K$ & 0.53 & 0.53 & 0.45 & 0.37 & & \\
\hline$b$ & 6.81 & 6.35 & 6.45 & 11.60 & & \\
\hline$W P_{\text {sigmid }}$ & 0.56 & 0.50 & 0.50 & 0.56 & $0.530 \pm 0.053$ & $7 \mathrm{Sept}-15 \mathrm{Oct}$ \\
\hline$\Omega$ & 15.01 & 15.14 & 14.66 & 12.37 & & \\
\hline$R^{2}$ & 0.637 & 0.759 & 0.886 & 0.779 & & \\
\hline \multicolumn{7}{|l|}{ VBG o } \\
\hline$L_{\mathrm{co}}$ & 22.19 & 25.09 & 28.71 & 23.74 & & \\
\hline$K$ & 0.93 & 0.72 & 0.55 & 0.74 & & \\
\hline$\Omega$ & 20.53 & 18.04 & 15.68 & 17.45 & & \\
\hline $\mathrm{R}^{2}$ & 0.792 & 0.765 & 0.825 & 0.817 & & \\
\hline \multicolumn{7}{|l|}{$\mathrm{VBG}_{\text {sine }} \sigma^{\prime}$} \\
\hline$L_{\infty}$ & 22.14 & 25.31 & 31.44 & 24.56 & & \\
\hline$K$ & 0.91 & 0.70 & 0.46 & 0.66 & & \\
\hline $\mathrm{C}$ & 0.94 & 0.56 & 0.67 & 0.85 & & \\
\hline$W P_{\ldots}$ & 0.66 & 0.61 & 0.54 & 0.61 & $0.61 \pm 0.08$ & 25 Sept-22 Nov \\
\hline$\Omega$ & 20.04 & 17.62 & 14.56 & 16.14 & & \\
\hline $\mathrm{R}^{2}$ & 0.809 & 0.771 & 0.845 & 0.827 & & \\
\hline \multicolumn{7}{|l|}{$\mathrm{VBG}_{\text {sigma }} \sigma^{*}$} \\
\hline$L_{\infty}$ & 21.94 & 24.87 & 30.66 & 24.18 & & \\
\hline$K$ & 0.96 & 0.75 & 0.49 & 0.70 & & \\
\hline$b$ & 7.54 & 4.97 & 6.12 & 7.22 & & \\
\hline$W P_{\text {sig tititi }}$ & 0.59 & 0.53 & 0.50 & 0.56 & $0.54 \pm 0.07$ & $7 \mathrm{Sept}-25 \mathrm{Oct}$ \\
\hline$\Omega$ & 21.08 & 18.55 & 15.08 & 16.81 & & \\
\hline $\mathrm{R}^{2}$ & 0.808 & 0.771 & 0.845 & 0.826 & & \\
\hline \multicolumn{7}{|l|}{ VBG @ } \\
\hline$L_{\infty}$ & 27.78 & 29.33 & 31.92 & 35.38 & & \\
\hline$K$ & 0.610 & 0.501 & 0.476 & 0.371 & & \\
\hline$\Omega$ & 16.95 & 14.69 & 15.19 & 13.13 & & \\
\hline $\mathrm{R}^{2}$ & 0.755 & 0.834 & 0.942 & 0.833 & & \\
\hline \multicolumn{7}{|l|}{$\mathrm{VBG}_{\text {sine }}$ ? } \\
\hline$L_{\infty}$ & 27.99 & 30.04 & 36.29 & 37.46 & & \\
\hline$K$ & 0.59 & 0.47 & 0.33 & 0.318 & & \\
\hline C & 1.57 & 2.93 & 2.35 & 1.41 & & \\
\hline$W P_{\text {sine }}$ & 0.75 & 0.715 & 0.48 & 0.581 & $0.63 \pm 0.20$ & 21 Aug-14 Jan \\
\hline$\Omega$ & 16.40 & 14.15 & 1.93 & 11.91 & & \\
\hline $\mathrm{R}^{2}$ & 0.766 & 0.842 & 0.945 & 0.838 & & \\
\hline \multicolumn{7}{|l|}{$\mathrm{VBG}_{\text {sigma }} \%$} \\
\hline$L_{\mathrm{co}}$ & 27.89 & & 33.93 & 36.82 & & \\
\hline$K$ & 0.60 & & 0.39 & 0.33 & & \\
\hline$b$ & 13.2 & & 12.2 & 9.2 & & \\
\hline$W P_{\text {sigma }}$ & 0.739 & Failed & 0.508 & 0.574 & $0.61 \pm 0.30$ & $7 \mathrm{Jul}-10$ Feb \\
\hline$\Omega$ & 0.84 & & 13.37 & 12.26 & & \\
\hline $\mathrm{R}^{2}$ & 0.808 & & 0.946 & 0.855 & & \\
\hline
\end{tabular}



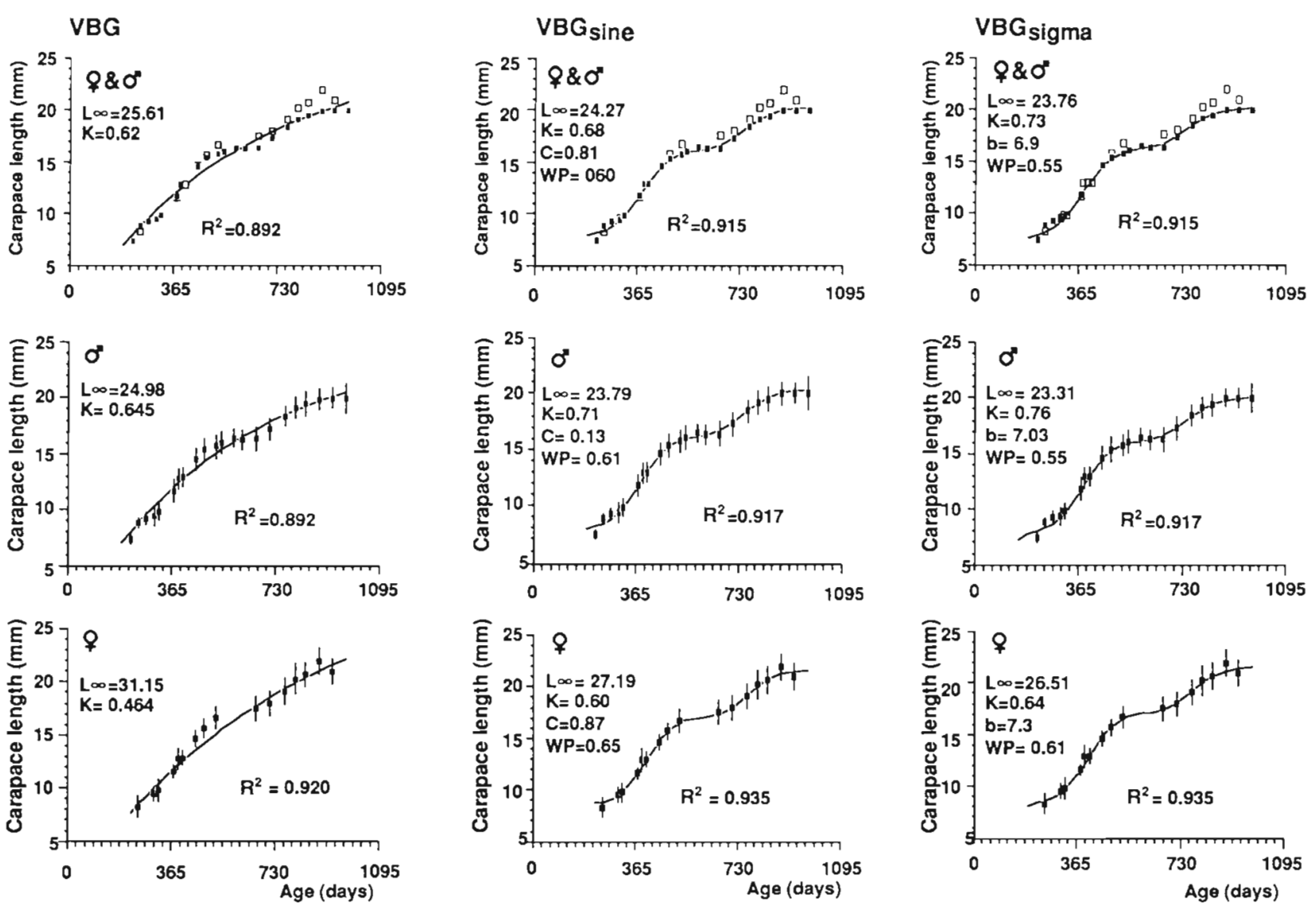

Fig. 4. Pandalus borealis. The 3 growth models [von Bertalanffy growth equation (VBG], VBG modified for seasonal growth by the addition of a sine function (VBG $\mathrm{Vine}_{\text {e }}$ (Pauly \& Gaschutz 1979) and the VBG with periodically recurring sigmoid functions ( $\left.V B G_{\text {sigma }}\right)$ developed for this study] fitted to the empirical mean sizes at age and standard deviations of the 1985 year class

during autumn-winter. Results also show a consistency of the predictions of the winter points between the 2 models.

\section{Differences between male and female growth patterns}

Table 2 and Fig 3 indicate differences in male and female growth rates when data are analysed 'year class wise'. Growth models fitted to female sizes by age weighted by number of shrimp generally yield lower $K$ and higher $L_{\mathrm{co}}$ than models fitted to male data. A statistical comparison of male and female $\Omega$ however, revealed that, irrespective of which growth model was fitted to the empirical data, the difference was only significant in all cases at the $75 \%$ confidence level (Table 4).

The estimates of the dates of slowest growth also differ (Table 2) between sexual stages when data are analysed 'year class wise'. This difference is significant at the $95 \%$ confidence level as shown by a statistical comparison of male and female winter points; $H_{0}$ : $W P_{\text {sineo }}=W P_{\text {sineo }}(p=0.0035)$, and $H_{0}: W P_{\text {sigma }}{ }^{*}=$ $W P_{\text {sigmao }}(\mathrm{p}=0.0099)$. Translated to the calendar year (Table 2) this means that the mean date of slowest growth occurred 2 to 3 mo later in the year (i.e. in the winter) for females than for males who experienced their slowest growth in the autumn.

Differences in male and female growth rates were also found when data from only the deep-water stagnation periods were analysed. Males generally had higher $K \mathrm{~s}$ and lower $L_{\infty} \mathrm{s}$ than females (Table 3). A comparison of $\Omega$ calculated from the estimated $K \mathrm{~s}$ and

Table 4. Pandalus borealis. Probabilities for $H_{0} \Omega_{\mathrm{o}^{*}}=\Omega_{\varphi}$

\begin{tabular}{|lcc|}
\hline Growth model & 'Year class wise' & 'Stagnation wise' \\
\hline $\mathrm{VBG}$ & $\mathrm{p}=0.1618$ & $\mathrm{p}=0.0609$ \\
$\mathrm{VBG}_{\text {sine }}$ & $\mathrm{p}=0.2254$ & $\mathrm{p}=0.0708$ \\
$\mathrm{VBG}_{\text {sigma }}$ & $\mathrm{p}=0.2358$ & $\mathrm{p}=0.1029$ \\
\hline
\end{tabular}


$L_{\infty}$ s (Table 4) shows a difference at the $90 \%$ confidence level.

The spans of slow growth periods determined from the winter points are presented in Table 3. In general the variation of WP estimates are wider than when data were analysed 'year class wise' and spans from mid summer to winter. The WPs estimated by the 2 models are relatively similar; $H_{0}: W P_{\text {sineo }}=$ $W P_{\text {sigma öo }}(\mathrm{p}=0.23)$; and $H_{0}: W P_{\text {sineq }}=W P_{\text {sigmaq }}(\mathrm{p}=$ 0.80 ). Only when male data were analysed separately could $H_{0}: W P_{\text {sine }}=W P_{\text {sigma }}$ be rejected at the $90 \%$ confidence level $(p=0.10)$. Similarly male and female winter points do not differ significantly when data from the water renewal periods are excluded; $H_{0}: W P_{\text {sine }}=W P_{\text {sineo }}(\mathrm{p}=0.71) ;$ and $H_{0}: W P_{\text {sigma }}=$ $W P_{\text {sigmaọ }}(p=0.36)$.

\section{Growth and temperature}

The result from the correlation analysis between ambient mean temperature and $\Omega$ (Table 5 ) shows that

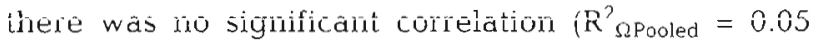
and $R_{\Omega \text { Male }}^{2}=0.456$ ) between these parameters in the investigated temperature interval in Gullmarsfjorden during the study years. Likewise no significant correlation $\left(R^{2}=0.003\right)$ was found between the regression coefficients of the CPL to age of the 1 to 2 yr old males and mean ambient temperature during deep water stagnation periods in Gullmarsfjorden.

Table 5. Pandalus borealis. Growth rate near $t_{0}(\Omega)$ calculated from the $V B G_{\text {sigma }}$ fitted to pooled and male sizes at age, and mean ambient temperatures observed during 4 different periods of deep-water stagnation in Gullmarsfjorden.

Temperature data from Bergström (1991b)

\begin{tabular}{|cccc|}
\hline $\begin{array}{c}\text { Stagnation } \\
\text { Year }\end{array}$ & $\begin{array}{c}\Omega \\
\sigma^{*}+q\end{array}$ & $\begin{array}{c}\Omega \\
\sigma^{*}\end{array}$ & $\begin{array}{c}\text { Mean temp. } \pm \mathrm{SD} \\
\left({ }^{\circ} \mathrm{C}\right)\end{array}$ \\
\hline 1984 & 15.00 & 21.08 & $5.88 \pm 0.11$ \\
1985 & 15.14 & 18.55 & $4.33 \pm 0.12$ \\
1986 & 14.66 & 15.08 & $4.56 \pm 0.21$ \\
1987 & 12.37 & 16.81 & $5.04 \pm 0.09$ \\
\hline
\end{tabular}

\section{Growth of Pandulus borealis in Gullmarsfjorden compared with other populations}

Comparisons of predicted sizes by age of females and males from Gullmarsfjorden with data from boreal waters (Table 6) indicated considerable similarities in growth patterns between northern shrimp in Gullmarsfjorden and other boreal populations. In no case could similarity between data from the different areas and CPL at age predicted by the mean $\mathrm{VBG}_{\text {sigma }}$ model be rejected as shown by consistently high probabilities for $H_{0}: \mathrm{CPL}_{\mathrm{A}}=\mathrm{CPL}_{\mathrm{B}}(\mathrm{p}=0.9821), H_{0}: \mathrm{CPL}_{\mathrm{A}}=\mathrm{CPL}_{\mathrm{C}}$ $(p=0.9776), H_{0}: C P L_{A}=C P L_{D}(p=0.9989)$, and $H_{0}: \mathrm{CPL}_{\mathrm{A}}=\mathrm{CPL}_{\mathrm{E}}(\mathrm{p}=1)$.

\section{DISCUSSION}

\section{Evaluation of growth models}

The coefficients of determination indicated that the growth models incorporating seasonal variations in growth consistently gave the best fit to the empirical data from Gullmarsfjorden (Fig. 4, Tables 2 \& 3). A similar situation was reported by Hopkins \& Nilssen (1990) who studied Pandulus borealis in Balsfjorden in northern Norway. The 3 models used here were also fitted to data from the North Sea (Alien 1959), Skagerrak (Torungen grounds) (Rasmussen 1953) and Oslofjorden (Rasmussen 1953). In these cases the highest coefficients of determination were also obtained for the seasonal models (Bergström unpubl.).

The 2 seasonal models used in this paper are both based on the VBG equation but they describe variations in growth in 2 different ways. The model presented by Pauly \& Gaschutz (1978) uses an attached sine function to depict the seasonal growth oscillations, while the new model presented in this study uses a sigmoid function. Despite the differences in construction, both models give in most cases similar results (Tables 2 \& 3). Exceptions are the results from fitting the sine model to female data analysed 'stagnation wise' which frequently gave $C$ values $>1$ indicating negative growth (shrinking) during winter. These results are biologically unreasonable for females because crustaceans change size through moulting and female shrimps carry their eggs attached to their pleopods during the winter. Thus if female shrimps substantially changed their size during winter it would be due to moulting which would result in shedding of the eggs together with the exuviae. Such a trait would dramatically decrease the reproductive fitness of the individual and consequently be eliminated by natural selection. This example illustrates the difficulty in using the model presented by Pauly \& Gaschutz (1978) on too few data which are spread far apart. In these cases the sine model needs restraints which can easily be incorporated by not allowing $C$ to exceed unity.

The $\mathrm{VBG}_{\text {sigma }}$ model does not allow negative growth. Another possible advantage is that the $\mathrm{VBG}_{\text {sigma }} \mathrm{com}$ bines sigmoid growth patterns with the VBG equation which in its unmodified form is unable to represent sigmoidal growth in a linear dimension (Gallucci \& Quinn 1979). Growth of macrobenthos is frequently sigmoidal 
Table 6. Pandalus borealis. Carapace length $(\mathrm{mm})$ by age predicted by mean male and female VBG $_{\text {sigma }}$ equations from Gullmarsfjorden together with reported carapace lengths from other boreal populations of Northern shrimp

\begin{tabular}{|c|c|c|c|c|c|c|c|c|c|c|c|c|c|}
\hline \multirow{3}{*}{$\begin{array}{l}\text { Age } \\
\text { (mo) }\end{array}$} & \multirow{2}{*}{\multicolumn{2}{|c|}{$\begin{array}{c}\mathrm{CPL}_{\mathrm{A}} \\
\text { Gullmarsfjorden, } \\
\text { Sweden }\end{array}$}} & \multicolumn{3}{|c|}{$C P L_{B}$} & \multirow{2}{*}{\multicolumn{3}{|c|}{$\begin{array}{c}\text { CPL }_{C} \\
\text { Burrard Inlet, } \\
\text { British Columbia, } \\
\text { Canada } \\
\text { (Butler 1964) }\end{array}$}} & \multirow{2}{*}{\multicolumn{3}{|c|}{$\begin{array}{c}\text { CPL } \\
\text { Gulf of Maine, } \\
\text { Maine, USA } \\
\text { (Haynes \& Wigley 1969) }\end{array}$}} & \multirow{2}{*}{\multicolumn{2}{|c|}{$\begin{array}{c}\text { CPLE } \\
\text { Oslofjorden, } \\
\text { Norway } \\
\text { (Rasmussen 1953) }\end{array}$}} \\
\hline & & & $\begin{array}{r}N \\
\text { Northu } \\
\text { (A }\end{array}$ & $\begin{array}{l}\text { orth } \\
\text { mber } \\
\text { len } 1\end{array}$ & $\begin{array}{l}\text { ea, } \\
\text { and, UK } \\
59)\end{array}$ & & & & & & & & \\
\hline & $0^{\prime \prime}$ & 甲 & $0^{7}$ & $\not$ & \% & o & $q^{\prime \prime}$ & $q$ & 0 & q & q & $\sigma$ & 9 \\
\hline 6 & 7.33 & 7.61 & 8.06 & & 9.05 & & & & 8.1 & & & & \\
\hline 8 & 8.37 & 9.78 & & & & 11 & & & & & & & \\
\hline 10 & 8.87 & 10.28 & & & & & & & 11.2 & & & 11.38 & \\
\hline 11 & 9.41 & 10.38 & & & & & & & & & & 12.00 & \\
\hline 12 & 10.28 & 10.50 & 13.01 & & 13.24 & 12.8 & & & & & & 12.25 & \\
\hline 13 & 11.47 & 10.77 & & & & & & & & & & 13.50 & \\
\hline 14 & 12.86 & 11.33 & & & & 14.3 & & & 14 & & & 14.18 & \\
\hline 15 & 14.18 & 12.37 & & & & & & & & & & 14.77 & \\
\hline 18 & 16.32 & 16.99 & 16.06 & & 17.2 & & & & 16.7 & & & & \\
\hline 19 & 16.56 & 17.82 & & & & 16.1 & & 16.1 & & & & 17.27 & \\
\hline 20 & 16.82 & 18.25 & & & & & & & & & & 17.47 & 19.70 \\
\hline 21 & 16.90 & 18.44 & & & & & & & & & & 17.87 & 18.45 \\
\hline 22 & 17.05 & 18.53 & & & & & & & 19 & & & 17.43 & 18.24 \\
\hline 24 & 17.72 & 18.66 & & 17.4 & 18.1 & & 18 & 17.8 & & & & & \\
\hline 25 & 18.29 & 18.82 & & & & & & & & & & 19.56 & 18.99 \\
\hline 26 & 18.95 & 19.14 & & & & & & & 20.8 & & & & \\
\hline 27 & 19.58 & 19.74 & & & & & & & & & & & \\
\hline 30 & 20.61 & 22.40 & & & & & & 20.6 & 22.4 & & & & \\
\hline 31 & 20.72 & 22.88 & & & & & & & & & & & 23.45 \\
\hline 32 & 20.84 & 23.13 & & & & & & & & & & & 23.20 \\
\hline 33 & 20.88 & 23.24 & & & & & & & & & & & 23.21 \\
\hline 34 & 20.96 & 23.30 & & & & & & & & 23.08 & & & 23.18 \\
\hline 35 & 21.08 & 23.33 & & & & & & & & & & & 23.38 \\
\hline 36 & 21.28 & 23.37 & & & 21.5 & & & & & & & & \\
\hline 38 & 21.86 & 23.65 & & & & & 22 & & & 24.90 & & & \\
\hline 42 & 22.65 & 25.53 & & & & & & & & & 25.8 & & \\
\hline 46 & 22.82 & 26.04 & & & & & & & & & 26.6 & & \\
\hline
\end{tabular}

with an inflection point early in life (Yamaguchi 1975). Thus variants of the $V_{B G} G_{\text {sigma }}$ model which combines sigmoid growth with the VBG may be useful not only for pandalid shrimp but also for other invertebrates. Theisen (1973) studying growth of lamellibranchs suggested that growth of all bivalves is sigmoidal and recommends a combined Gompertz-von Bertalanffy model.

The $\mathrm{VBG}_{\text {sigma }}$ model used in this study assumes a periodicity of $1 \mathrm{yr}$ in growth oscillation, which seems reasonable for pandalid populations at boreal latitudes. However, the literature, e.g. Rasmussen (1953), Teigsmark (1983) and Shumway et al. (1985), indicates that the periodicity may be more than 1 yr in Arctic stocks. The $\mathrm{VBG}_{\text {sigma }}$ model may easily be altered to describe any periodicity of oscillation by varying the constant $P$ in the $\mathrm{VBG}_{\text {sigma }}$ function. This may be an advantage not only for the Northern shrimp, but also for other species with oscillating growth.

Although seasonal models gave better fits to the observed carapace lengths no significant differences in $\Omega$ calculated from the $K$ s and $L_{\infty} s$ given by the 3 models could be shown. One practical implication of this finding may be that for detailed descriptions of growth in Pandalus borealis on a relatively fine temporal scale it may be advisable to use the more laborious seasonal models, while for studies where a fine temporal resolution is not needed the basic VBG equation may be sufficiently reliable.

Both winter points ( $W P_{\text {sine }}$ and $W P_{\text {sigma }}$ ) give the time for slowest growth of the year (Pauly \& Gaschutz 1978, and present paper). Since the mean CPL of shrimp at the date of slowest growth (WP) is the result of the growth during the previous growing season, knowledge about the periodicity of the growth stagnations might result in more cost-efficient sampling programs. Mean sizes by age calculated from samples taken during the growth stagnation periods (autumn and winter in most cases) would fall as discrete points along a VBG-like curve. Such a practice would not give the detailed picture of the growth pattern that the fitting of more advanced continuous growth models provides, but may be sufficient for monitoring of 
growth increments in populations for which growth patterns have been thoroughly analysed beforehand.

The only other study of winter growth (Hopkins \& Nilssen 1990) defines the winter points 'as the turning point in time when the seasonally stagnated growth terminates and the growth rate become elevated again' These authors report winter points ranging between 0.86 and 1.07 . If these winter points are translated to the calendar year $\{[(W P \times 365)+106] / 30.41=$ no. of elapsed months since the beginning of the year\} using 15 April as the mean hatching date (Hopkins \& Nilssen 1990) the growth stagnation terminates and growth becomes elevated again between 14 November and 9 May (i.e during late autumn-early spring). This is puzzling since a visual inspection of the graphs of mean carapace lengths at sampling date given by these authors indicates that the growth stagnation period lasts from December to early April.

\section{Differences in male and female growth}

Iin thie literature and in siock assessment, yluwih models are mostly fitted to pooled male and female Pandalus borealis data (Fréchette \& Parsons 1981). This procedure assumes that growth is similar for the sexual stages in this sequential hermaphrodite and that growth in carapace length can be described by the same growth model parameters for both sexual stages. However, there are numerous indications in the literature that there are differences in growth pattern between the sexes. Allen (1959), for example, reports that female shrimp in Northumberland, UK, waters grew faster than male shrimp. Similarly in Rasmussen's (1953) classical study male shrimp are generally reported to be smaller at age than females along the Norwegian coast. Results from Gullmarsfjorden also indicate differences in growth patterns between sexual stages (Tables 2,3 \& 4, Fig. 3), although they are less clear cut. Differences in growth rate (expressed as $\Omega$ ) could only be shown at the $75 \%$ confidence level, probably due to the relatively small number of observations. However, both the analyses of growth based on year classes and deepwater stagnation periods show a significant $195 \%$ level) difference in growth seasonality between sexual stages. The winter data from both seasonal growth models indicate that growth in length generally declines during autumn to late winter, but the average $W P$ indicates that the male decline in growth starts earlier than the female in Gullmarsfjorden (Tables $2 \& 3$ ). This holds especially true when data were analysed 'year class wise' When data were analysed 'stagnation wise' the results were less conclusive, probably because the models were fitted to fewer samples (samples obtained during the water renewal periods were excluded).

The beginning of the growth plateau in females coincides with the mating season and may be explained by allocation of resources from somatic growth in length during spring and summer to investment in ovaries during later summer and autumn (Bergström 1991b). After spawning in late September-early October, females do not change size by moulting because the eggs are carried attached to the pleopods during winter, thus prolonging the growth stagnation period in females. Female growth starts again the next year in the spring with the post-hatching moult which occurs after hatching in late March-early April in Gullmarsfjorden (Bergström 1991b)

Explanations for the decrease in male somatic growth may include the allocation of energy and matter for testicular development, and swimming activity before and during the mating period. However, males may start to grow in length just after mating because they are not hampered by carrying likeir ofíspring ailacheu io ineir exoskeleion. For maies about to change sex, the physiological processes connected with sex change may also take resources from growth in length during late autumn-early winter. In Gullmarsfjorden, shrimps with external transitional morphology were mostly found in winter-early spring, i.e. after the male growth stagnation period had ended (Figs. $2 \& 5$ ).

These explanations of the seasonally varying growth pattern are tied to the reproductive biology of Pandalus borealis instead of to environmental factors such as food, temperature, etc., which of course ultimately affect the life of pandalid shrimps. Alternative explanations for the seasonal growth variations in relation to the reproductive cycle of $P$. borealis might be that variations in temperature and availability of food directly affect growth. Temperature variations at depths where $P$. borealis are found in Gullmarsfjorden (Table 5) and other investigated areas (Shumway et al. 1985) are, however, exceedingly small over the year. This makes seasonal temperature variations unlikely as a factor causing seasonal growth, especially since mean ambient temperature and growth rate did not correlate in the temperature interval of approximately 4 to $6{ }^{\circ} \mathrm{C}$ in Gullmarsfjorden during the years studied (Table 5). Considering the availability of food, $P$. borealis is reported to be able to feed both on pelagic and benthic organisms (Wienberg 1981). In addition it shows scavenging habits, since it can be caught in baited traps (Barr \& MacBride 1967). All of these food categories were represented in abundance in the fjord during the study period. 
Still another possibility is that the relatively low oxygen content of the water in the deep basin may hamper growth towards the end of the deep-water stagnation period (autumn-winter); however because seasonal growth oscillations are found in most of the distributional area of Pandalus borealis (Shumway et al. 1985) this explanation also seems unlikely.

Results indicate differences in growth seasonality and rate between sexual stages. Therefore growth in this sequential hermaphrodite either is best described by the combination of a male and a female growth curve instead of just one for both stages. Such a model should also combine the growth of the 2 sexes in relation to their proportional occurrence in the population. In populations of Pandalus borealis living in boreal latitudes, the female part of the population may be composed of a mixture of specimens of different ages with different sex change histories (Charnov 1979, Charnov 1982, Charnov \& Bergström 1987). This mixture may consist of varying proportions of shrimp which breed only as females (primary females) and shrimp that either have changed sex to females before their first reproduction (early maturing females) or in time for their second or third reproduction. These females all contribute to the average female growth curve in proportion to their occurrence together with the male shrimps in the population. Fig. 5 illustrates a graphical attempt to depict this branching off of females during the life of a hypothetical year class based on the average male and female VBG curves with sigmoid seasonal oscillations from Gullmarsfjorden. Worth noting is that these 2 curves are averages of all 7 year classes studied in the fjord. The fitting of the initial male and female curves were done on mean cohort CPL weighted by number of shrimp in the cohort, thus small/young females and large/old males which occur in low pro- portions contribute to the curves in relation to their occurrence. In Fig. 5 there are 2 time scales one indicating age and one indicating dates. As shown in this figure male growth declines less, earlier, and for a shorter period than female growth. The occurrence of transitional shrimps mostly coincides with the latter part of the male growth stagnation period (winterearly spring).

\section{Growth and temperature}

Very little is known about which ecological factors affect growth in Pandalus borealis. The most discussed factor in the literature is ambient temperature which is considered to explain differences in age at first spawning (Apollonio et al. 1986) and CPL at age (Shumway et al. 1985). My results from the temporally isolated shrimp populations in Gullmarsfjorden growing at different mean ambient temperatures during different deep water stagnation periods indicate that there is no correlation between temperature and growth rate within the temperature interval of 4 to $6^{\circ} \mathrm{C}$. A similar observation was made by Parsons et al. (1989) comparing Northern shrimp growth in the temperature interval of 2 to $4{ }^{\circ} \mathrm{C}$ from 4 regions of the Northwest Atlantic.

However a comparison of CPL at age from Gullmarsfjorden with literature data from Arctic populations (cited by Hopkins \& Nilssen 1990) show that Arctic shrimp are substantially smaller by age. Hopkins \& Nilssen (1990) stated that 'although ... on a broad latitudinal scale age at first spawning can be correlated with ambient temperature there might be more important overriding factors than temperature at any one locality' My conclusions from Gullmarsfjorden agree with this statement.
Fig. 5. Pandalus borealis. Average growth curve $\left(\mathrm{VBG}_{\text {sigma }}\right)$ for males and females in boreal waters based on data from year classes 1980 to 1986 in Gullmarsfjorden from 1984 to 1987. Average sizes of transitional shrimp are indicated as points (*)

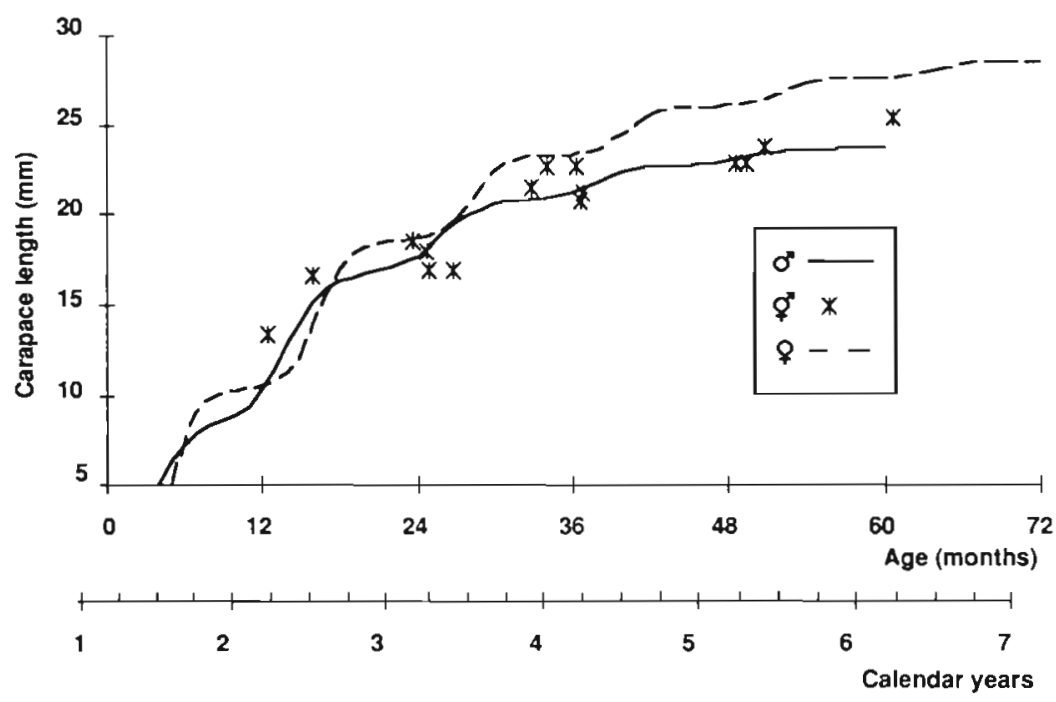




\section{Comparison with other boreal populations}

Data in this study were both analysed 'year class wise' and 'stagnation wise' to see if yearly immigrations of adult shrimp (Bergström 1991a) from the neighbouring larger Skagerrak population affected growth estimates made on the fjord demes of shrimps. Results indicate substantial similarities in the estimates of growth obtained by analysing data following year classes and by analysing data exclusively from the deep-water stagnation periods. This result corroborates the conclusion that stagnation populations of Pandalus borealis in Gullmarsfiorden should be viewed as periodical isolates of the larger Skagerrak stock (Bergström 1991a) and thus may reflect general growth patterns. This conclusion is further supported by comparisons of size by age predicted by male and female mean $V_{B G} G_{\text {sigma }}$ curves and sizes by age from other boreal populations of the Northern shrimp (Table 6). The sizes by age predicted by the average male and female models with sigmoid oscillations in growth derived from Gullmarsfjorden are in good agreement with sizes by age in most populations from boreal latitudes. A comparison of sizes by age with 2 Arctic populations, Balsfjorden (Hopkins \& Nilssen 1990) and the Barents Sea (Teigsmark 1983), however, shows that shrimps in these populations are consistently smaller at similar ages than in Gullmarsfjorden, which may illustrate that growth rates of $P$. borealis decrease with increasing latitude as suggested, for example, by Rasmussen (1953) and Shumway et al. (1985).

Acknowledgements. The Pandalus project has been supported by the Kristineberg Marine Biological Station since 1984. Prof. J.-O.Strömberg offered constant support without which this study could not have been performed. In 1988 partial funding was received from the Swedish Natural Science Research Council and the County Board of Nature Conservancy in Gothenburg, and since 1990 from the Faculty for Mathematics and Natural Sciences and the Marine Research Centre, University of Göteborg. The Institute of Marine Research in Lysekil gave technical assistance through A.-M. Bratt, $Y$ Ericsson and J.-O. Pettersson and the crew of the RV 'Arne Tiselius' assisted with the trawling. $M$. Andersson and B. Wennberg, the Gothenburg Center for Applied Mathematics, Chalmers University of Technology, gave invaluable help with the growth model and general statistical advice. Helpful comments on the manuscript were given by $M$. Andersson, R. A. Brown, E. Charnov, D. G. Parsons, V. Siegel, B. Sjöstrand, J.-O. Strömberg and I. Svane.

\section{LITERATURE CITED}

Allen, J. A. (1959). On the biology of Pandalus borealis (Kroyer), with reference to a population of the Northumberland coast. J mar. biol. Ass. U.K. 38: 189-220

Apollonio, S., Stevenson, D. K., Dunton, E. E. (1986). Effects of temperature on the biology of the northern shrimp
Pandalus borealis, in the Gulf of Maine. NOAA Tech. Rep. 22. NMFS, U.S. Dept Commerce

Barr, L., MacBride, R. (1967). Surface-to-bottom pot fishing for pandalid shrimp. U.S. Fish Wild. Serv. Spec. Sci. Rep. Fish. 560: 1-7

Bergström, B. I. (1989). Preliminary results on growth and age determination of Pandalus borealis (Krøyer) in periodically enclosed fjord populations. Northwest Atlantic Fisheries Organisation (NAFO), SCR Doc. 89. Serial No. N1690

Bergström, B. 1. (1991a). Yearly immigration of Northern shrimp Pandalus borealis (Kroyer) into perodically isolated fjord populations. Sarsia 76: 133-140

Bergström, B. 1. (1991b). Reproductive cycle and the effect of temperature on oogenesis of Pandalus borealis (Krøyer). J. Shellfish Res. 10(2): 327-331

Berkely, A. A. (1930). The post-embryonic development of the common pandalids of British Columbia. Contr. Can. Biol. N.S. 6: $79-163$

Beverton, R. J. H., Holt, S. J (1957). On the dynamics of exploited fish populations. Fish Invest. Minist. Agric. Fish Food G.B. Ser. II Salmon Freshwat. Fish 19:1-533

Butler, T H. (1964). Growth, reproduction, and distribution of pandalid in British Columbia. J. Fish. Res. Bd Can. 21 $1403-1452$

Charnov, E. L. (1979). Natural selection and sex change in pandalid shrimp: test of a life history theory. Am. Nat. 113 $515-734$

Charnov, E. L. (1982). The theory of sex allocation. Princeton University Press, Princeton, New Jersey

Charnov, E. L., Bergström, B. I. (1987). Alternative life histories in sex changing shrimp: a phenotype limited ESS Evol. Ecol. 1: 107-111

Ettershank, G. (1984). A new approach to the assessment of longevity in the Antarctic krill Euphausia superba. J. Crust. Biol. 4 (1): 295--305

Fréchette, J., Parsons, D. G. (1983). Report of shrimp ageing workshop held at Ste. Foy, Quebec, in May and at Dartmouth, Nova Scotia, in November 1981. NAFO Sci. Counc. Stud. 6: 79-100

Gallucci, V. F., Quinn, T J. (1979). Reparameterizing, fitting, and testing a simple growth model. Trans. Am. Fish. Soc. 108: $14-25$

Haynes, E. B., Wigley, R. L. (1969). Biology of the northern shrimp, Pandalus borealis, in the Gulf of Maine. Trans. Am. Fish. Soc. 98: 60-76

Hopkins, C. C. E., Nilssen, E. M. (1990). Population biology of the deep water prawn (Pandalus borealis) in Balsfjord, northern Norway: I. Abundance, mortality and growth, 1979-1983. J. Cons. int. Explor. Mer 47: 148-166

Hopkins, C. C. E., Nilssen, E. M., Hermannsen, A., Vaaja, B. Dalsbe, L. (1989). Body composition and energetic predictors of age/season in the prawn Pandalus borealis. Int. Counc. Explor. Sea (ICES). Doc. C.M. 1989/K: 10, Ref. D

Lindahl, O., Hernroth, L. (1988). Large scale and long-term variations in the zooplankton community of the Gullmarfjord, Sweden, in relation to advective processes. Mar. Ecol. Prog. Ser. 43: 161-171

Macdonald, P. D. M. (1987). Analysis of length-frequency distributions. In: Summerfelt, R. C., Hall, G. E. (eds.) Age and growth of fish. Iowa State University Press, Ames, p. $371-384$

Macdonald, P. D. M., Pitcher, I J. (1979). Age-groups from size-frequency data: a versatile and efficient method of analysing distribution mixtures. J. Fish. Res. Bd Can. 36: $98 \overline{7}-1001$ 
Parsons, D. G. (1989). Report of the working group on progress in age determination of Pandalus. Northwest Atlantic Fisheries Organisation (NAFO), SCR Doc. 89/22. Serial No. N 1700

Parsons, D. G., Mercer, V. L., Veitch, P. J. (1989). Comparison of the growth of Northern shrimp (Pandalus borealis) from four regions of the Northwest Atlantic. J. Northw. Atl. Fish. Sci. 9: 123-131

Pauly, D., Gaschutz, G. (1978). A simple method of fitting oscillating length growth data with a programme for pocket calculations. Comm. Meet. int. Coun. Explor. Sea C.M.-ICES/G: 24

Rasmussen, B. (1953). On the geographical variation in growth and sexual development of the deep-sea prawn (Pandalus borealis $\mathrm{Kr}$ ). Report on Norw. Fish. Mar. Invest. 10(3): 1-160

Shumway, S. E., Perkins, H. C., Schick, D. F., Stickney, A. P. (1985). Synopsis of biological data of the pink shrimp Pandalus borealis (Krøyer, 1838). NOAA Technical Report NMFS 30 (FAO Fisheries Synopsis No. 144), p. 57

This article was submitted to the editor
Skúladóttir, U. (1985). Tagging and recapture results of Pandalus borealis (Kroyer) in Icelandic waters. Comm. Meet. int. Coun. Explor. Sea C.M.ICES/ G: 42

Sokal, R. R., Rohlf, F. J. (1969). Biometry. W. H. Freeman \& Co., San Fransisco, p. 776

Teigsmark, G. (1983). Populations of the deep-sea shrimp (Pandalus borealis Krøyer) in the Barents Sea. FiskDir Skr. Ser. Havunders. 17: 377-430

Theisen, B. (1973). The growth of Mytilus edulis L. (Bivalvia) from Disco and Thule district. Greenland. Ophelia 12: $59-77$

von Bertalanffy, L. (1938). A quantitative theory of organic growth. Hum. Biol. 10: 181-213

Wienberg, R. (1981). On the food and feeding habits of Pandalus borealis Krøyer 1838. Arch. FischWiss. 31: $123-137$

Yamaguchi, M. (1975). Estimating growth parameters from growth rate data. Oecologia 20: 321-332

Manuscript first received: February 12, 1992

Revised version accepted: April 27, 1992 